\title{
Rank University Websites Using Fuzzy AHP and Fuzzy TOPSIS Approach on Usability
}

\author{
Renuka Nagpal \\ Amity School of Engineering and Technology, Noida, 201301, India \\ Email: rnagpal1@amity.edu \\ ${ }^{*}$ Deepti Mehrotra, ${ }^{\#}$ Pradeep Kumar Bhatia and ${ }^{+}$Arun Sharma \\ *Amity School of Engineering and Technology, Noida, 201301, India \\ \#Guru Jambeshwar University, Hisar, 125001, India \\ ${ }^{+}$Indira Gandhi Delhi Technical University, New Delhi-110006, India \\ Email: * mehhdeepti@gmail.com," pkbhatia.gju@gmail.com, "arunsharma2303@gmail.com
}

\begin{abstract}
With the advent of dynamic website usually all business processes of a business organization are linked with the website of the organization. This is resulted in designing of a complex and gigantic website which may result in slow download and unfriendly navigation. Satisfying the end user need is one of the key principles of designing an effective website. As there are different users for given website, hence there are different criteria on which user wants to get satisfied, hence evaluating a website is a multi-criteria decision making problem. In order to incorporate uncertainties and vagueness in decision making Fuzzy Analytic Hierarchy (FAHP) approach is extended with Fuzzy TOPSIS approach, where different decision makers (DM's) opinion was considered for ranking the website.
\end{abstract}

Index Terms-Usability, website, FAHP, F-TOPSIS, Ranking

\section{INTRODUCTION}

Websites has become an integral part of any organization. Apart from being used as a virtual image and promotional platform of the organization for displaying all features and facility of the organization, now its functionality is enhanced for facilitating all business process. Today almost all business application processes are linked with web portal. Usability, Security and Reliability are important factors for evaluating the success of any website. Usually usability of website is measured after website is launched depending on user satisfaction and his navigation, download time; accessibility etc. In order to increase the effectiveness of the website there is a need to integrate usability prediction and estimation at each stage of the website design.

The websites are designed keeping a view of end users and their needs. As different users have different choices and different cognitive approach to access the website, hence achieving high user satisfaction i.e. high usability is a prime challenge for website designers. The ease with which the user can fetch the desired information determines the success and failure of that website. The usability of a website is directly related with the success

of the organization as it helps the visitors to search particular information and then make a subsequent decision for using that product. The overall popularity of any organization is directly proportional to the number of visitors and their usage of the organizational website. How website helps the user to achieve their objectives and how well website responds to user requirements decides the effectiveness of website.

A large amount of research has been done to evaluate performance and effectiveness of the website using formal algorithms that also integrate the customer prospective. Bevan [1] had proposed standard and guidelines for web usability. Evaluating usability of the website and including its inputs in web development process will increase overall success of website. Usability depends upon various factors as discussed by [2] [3]; it is a Multi Criteria Decision Making (MCDM) problem. MCDM deals with the problems where we need to choose an option from a set of alternatives which are characterized by different criteria. Identifying the criteria that are most critical for a given domain is an important aspect for decision making. The decision maker rank for these criteria by proposing the weights /importance. As these weights can't have a crisp value so they may be rated on Saaty's Scale [4] where these weights are expressed as linguistic variables. There are various MCDM approaches available in the literature. Most popular among them are CP(Compromise Programming)[5],ELECTRE I,ELECTRE II,ELECTRE III(Elimination Et choix Traduisant la Realite) $[6,7,8]$ Analytic Hierarchy Process (AHP)[9], Technique for Order Preference by Simulation of Ideal Solution(TOPSIS) [10], Preference Ranking Organization Method for Enrichment Evaluations (PROMTHEE) [11] Analytic Network Process (ANP)[12] etc. These techniques are used for choosing the best alternative where there are a group of decision makers. In order to handle uncertainty, subjectivity and vagueness of response, the fuzzy set theory [13] was incorporated in various MCDM approaches and these methods were modified to Fuzzy AHP[14], Fuzzy TOPSIS[15] etc. 
As each website has different features and different user also has different requirements, the criteria's that should be considered for evaluating the websites are different. Researchers have tried to identify the parameters which are most important for given website depending on the user feedback collected from wide range of user who will possibly visits website frequently [16]. In this paper websites of different Universities are considered as a case study where the decision makers considered are expert web designers. Like other industries the websites are becoming the key entry point for the aspiring students and their parents for selecting an educational organization. As the online technologies has become a key source for information retrieval there is need to have a reliable informative and effective website which can cater the need of wide range of viewers. Further these websites provides many features like online attendance, marks verification etc. which are the integral component of education process. Blending the user's satisfaction and the need of education processes (admission regular monitoring, examination etc.) made the website designing a complex process.

Measuring the effectiveness of website by merely counting the hits on the pages or only one criterion like ease of navigation etc. is not accurate. Choosing the website depending on the given criteria (user perspective) among the given alternatives is essentially a decision process. For the universities websites the criteria on which the usability depends are Response Time (RT), Ease of Use (EOU), Ease of Navigation (EON) and Informative (INF). To deal with uncertainty fuzzy set theory along with Multi Criteria Decision Making (MCDM) has been extensively used. Hence there is a need to use an effective usability measurement technique which can suffix MCDM approach for these websites.

\section{FUZZY THEORY}

Fuzzy sets introduced by [13] extended the classical definition of sets, deals with the vagueness of human thoughts. In classical set an element either belongs completely or completely excluded from the set. In fuzzy set the elements does not have well defined crisp values, the element can partially belong to the set.

\section{A. Membership Function}

Fuzzy sets are characterized by membership function that assigns each element a value between 0 and 1 which can be represented as:

$$
\mu_{A}: X \rightarrow[0,1]
$$

"For a fuzzy set A, X is the universe of discourse whose each element are assigned the value between 0 and 1 '. [12]

\section{B. Triangular Fuzzy numbers}

Membership functions allow fuzzy sets to be represented graphically .The widely adopted triangular fuzzy number (TFN) approach is used to represent the uncertainty or vagueness of linguistic terms as shown in Fig. [1].

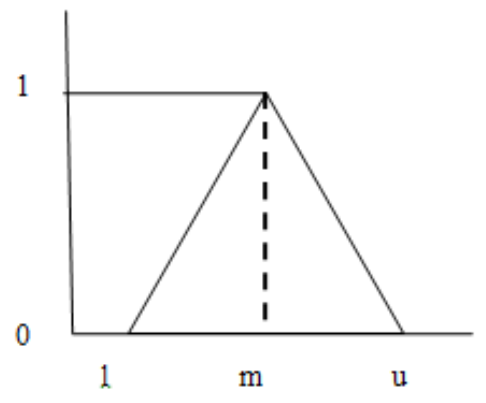

Fig. 1 Fuzzy Number with triangular membership functions

A TFN can be defined by a lower limit 1, an upper limit $\mathrm{u}$, and a value $\mathrm{m}$, where $1<\mathrm{m}<\mathrm{u}$ as given below using the membership function [17]:

$$
\mu_{A}(x)=\left\{\begin{array}{ll}
\frac{x-l}{m-l} & 1 \leq \mathrm{x} \leq \mathrm{m} ; \\
\frac{\mathrm{m}-\mathrm{x}}{\mathrm{u}-\mathrm{m}} & \mathrm{m} \leq \mathrm{x} \leq \mathrm{u} ; \\
0 & \text { otherwise }
\end{array}\right\}
$$

\section{Linguistic Variable}

According to Zadeh [18] linguistic variable are variables whose values are represented in words or sentences in a natural or artificial language. Linguistic variable are used in such situation that are complicated and hard to define. The linguistic approach is found useful in humanistic systems like Artificial Intelligence, Opinion Mining Information Retrieval and the related areas. As an example, height can be given exact value; but if we need to compare the group of people on scale of height we describe it as short, very short, tall etc. Hence demarking this group on exact height sets is not correct like $150 \mathrm{~cm}$ is short and $151 \mathrm{~cm}$ is tall. In such a case where comparison has some vagueness linguistic fuzzy variables are better choice than exact value. In fuzzy set theory, for transforming the linguistic terms into fuzzy numbers the conversion scale of 1 to 9 is used for rating the criteria and alternatives. The relationship between fuzzy number and corresponding linguistic variable identifying the important weights for each criteria and membership function is given below in Table 1

Table 1 Linguistic variable for importance weight of each criteria

\begin{tabular}{|l|l|l|}
\hline $\begin{array}{l}\text { Fuzzy } \\
\text { number }\end{array}$ & Linguistic Scales & Membership function \\
\hline 1 & Equally Important & $1,1,1$ \\
\hline 3 & Weak important & $1,3,5$ \\
\hline 5 & $\begin{array}{l}\text { Essentially } \\
\text { Important }\end{array}$ & $3,5,7$ \\
\hline 7 & $\begin{array}{l}\text { Very strongly } \\
\text { important }\end{array}$ & $5,7,9$ \\
\hline 9 & $\begin{array}{l}\text { Absolutely } \\
\text { Important }\end{array}$ & $7,9,9$ \\
\hline
\end{tabular}




\section{Algebraic Operations with Fuzzy numbers}

If $A=\left(l_{1}, m_{1}, u_{1}\right)$ and $B=\left(l_{2}, m_{2}, u_{2}\right)$ are two triangular fuzzy numbers, various arithmetic operations that can be performed related to fuzzy numbers with triangular membership function are $[19,20,21]$ for $l_{1}, l_{2} \geq 0$ :

Addition of two TFN's

$$
A(+) B=\left(l_{1}+l_{2}, m_{1}+m_{2}, u_{1}+u_{2}\right)
$$

Subtraction of two TFN's

$$
A(-) B=\left(l_{1}-l_{2}, m_{1}-m_{2}, u_{1}-u_{2}\right)
$$

Multiplication of two TFN's

$$
A(\times) B=\left(l_{1} l_{2}, m_{1} m_{2}, u_{1} u_{2}\right)
$$

\section{Methodology}

In this paper we have ranked the university websites using the steps taken in Fig. 2 The case study includes the four university websites having same strength of students and functionalities. Hence they are evaluated on the same criteria's. MCDM approach is used in which the weights of each criteria is measured using FAHP and ranking is done through Fuzzy TOPSIS. In FAHP the pair wise comparison of criteria and alternatives are made and hence it is used to evaluate the weight of the criteria. Using these weights the websites are ranked by FuzzyTOPSIS where the best alternative is identified by considering the one having nearest positive ideal solution and farthest negative ideal solution. Each step is discussed in detail in the trailing section.

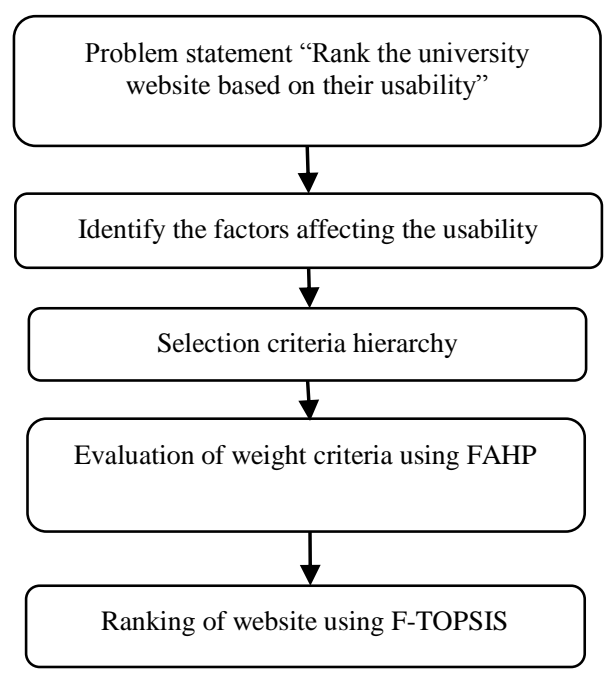

Fig 2: Steps of the Proposed Method

\section{A. Criteria that determines the Usability of Website}

Based on detailed literature survey [2] and the user feedback the four parameters RT, EOU, EON and INF are identified as most crucial for determining the usability of websites of institutes of higher education. The various parameters which affect these criteria's were identified and a checklist was prepared as given in Table 2 on which experts evaluated the university websites.

\section{B. Selection Criteria Hierarchy}

Based on the identified criteria four university websites were ranked. The hierarchical structure of the problem is shown in Fig. 3

\section{FAHP Approach to Determine The Criteria Weight}

i. Obtain the Normal paired comparability matrices (NPC) using AHP method and convert it into Fuzzy NPC using Table 1 as shown in Table 3.

Table 3 Fuzzy NPC matrix

\begin{tabular}{|l|l|l|l|l|}
\hline C1 & $(1,1,1)$ & $(1,3,5)$ & $(3,5,7)$ & $(1,1 / 3,1 / 5)$ \\
\hline C2 & $(1,1 / 3,1 / 5)$ & $(1,1,1)$ & $(1,3,5)$ & $(1,1 / 3,1 / 5)$ \\
\hline C3 & $\begin{array}{l}(1 / 3,1 / 5, \\
1 / 7)\end{array}$ & $(1,1 / 3,1 / 5)$ & $(1,1,1)$ & $(1 / 3,1 / 5,1 / 7$ \\
\hline C4 & $(1,3,5)$ & $(1,3,5)$ & $(3,5,7)$ & $(1,1,1)$ \\
\hline
\end{tabular}

ii. Applying the fuzzy extent analysis [22] to convert the fuzzy NPC into its corresponding criteria weights

$$
\begin{aligned}
& \mathrm{S}_{\mathrm{i}}=\sum_{\mathrm{j}=1}^{\mathrm{m}} \mathrm{M}_{\mathrm{i}}^{\mathrm{j}} \times\left[\sum_{\mathrm{i}=1}^{\mathrm{n}} \sum_{\mathrm{j}=1}^{\mathrm{m}} \mathrm{M}_{\mathrm{i}}^{\mathrm{j}}\right]^{-1}=\mathrm{W}= \\
& {\left[\mathrm{w}_{1}, \mathrm{w}_{2}, \ldots ., \mathrm{w}_{\mathrm{n}}\right]}
\end{aligned}
$$

Where $S_{i}-$ Value of fuzzy synthetic extent w.r.t $i^{\text {th }}$ criteria.

$$
\begin{gathered}
\mathrm{M}_{\mathrm{i}}^{\mathrm{j}}(\mathrm{j}=1,2, \ldots, \mathrm{m}) \text { are TFN's } \\
\sum_{\mathrm{j}=1}^{\mathrm{m}} \mathrm{M}_{\mathrm{i}}^{\mathrm{j}}=\left(\sum_{\mathrm{j}=1}^{\mathrm{m}} \mathrm{l}_{\mathrm{j}} \sum_{\mathrm{j}=1}^{\mathrm{m}} \mathrm{m}_{\mathrm{j}} \sum_{\mathrm{j}=1}^{\mathrm{m}} \mathrm{u}_{\mathrm{j}}\right)
\end{gathered}
$$

As per Table [3] using eq. (7)

$$
\begin{aligned}
{\left[\sum_{\mathrm{i}=1}^{\mathrm{n}} \sum_{\mathrm{j}=1}^{\mathrm{m}} \mathrm{M}_{\mathrm{i}}^{\mathrm{j}}\right]^{-1} } & =[18.66,27.72,39.08]^{-1} \\
& =\left[\frac{1}{39.08}, \frac{1}{27.72}, \frac{1}{18.66}\right]
\end{aligned}
$$

And using eq. (6)

$$
\begin{gathered}
\mathrm{S}_{\mathrm{c} 1}=\sum_{\mathrm{j}=1}^{\mathrm{m}} \mathrm{M}_{\mathrm{i}}^{\mathrm{j}} \times\left[\sum_{\mathrm{i}=1}^{\mathrm{n}} \sum_{\mathrm{j}=1}^{\mathrm{m}} \mathrm{M}_{\mathrm{i}}^{\mathrm{j}}\right]^{-1}=(6,9.33,13.2) \times \\
\left(\frac{1}{39.08}, \frac{1}{27.72}, \frac{1}{18.66}\right)=(0.15,0.34,0.7)
\end{gathered}
$$

In the similar pattern the weights for other criteria $(\mathrm{C} 2$, $\mathrm{C} 3$, and C4) is calculated and shown in Table 4.

Table 4 Criteria Weights using FAHP

\begin{tabular}{|c|c|}
\hline Decision Criteria & Weights \\
\hline $\mathrm{Wc} 1=\mathrm{Sc} 1$ & $(0.15,0.34,0.7)$ \\
$\mathrm{Wc} 2=\mathrm{Sc} 2$ & $((0.10,0.17,0.34)$ \\
$\mathrm{Wc} 3=\mathrm{Sc} 3$ & $((0.06,0.06,0.08)$ \\
$\mathrm{Wc} 4=\mathrm{Sc} 4$ & $(0.15,0.43,0.96)$ \\
\hline
\end{tabular}


Table 2 Criteria affecting the usability of a website.

\begin{tabular}{|c|c|c|c|}
\hline S.No. & Criteria & Sub criteria & Checklist \\
\hline 1 & Response Time & $\begin{array}{l}\text { Download time } \\
\text { Query Processing } \\
\text { Downloading the home } \\
\text { page } \\
\text { Image download }\end{array}$ & $\begin{array}{l}\text { Time taken to download any information } \\
\text { How fast the query is processed. } \\
\text { How fast homepage is } \\
\text { downloaded } \\
\text { How fast Images and Animation gets downloaded. }\end{array}$ \\
\hline 2 & Ease of Use & $\begin{array}{l}\text { Learnability } \\
\text { Change in architecture. } \\
\text { Interactivity with the user. } \\
\text { Browser Compatibility }\end{array}$ & $\begin{array}{l}\text { How easy is to learn the website } \\
\text { How less frequently the complete architecture and the look of } \\
\text { website changes. } \\
\text { Clear Instructions, help functions and feedback. } \\
\text { How compatible website is with the different browser. }\end{array}$ \\
\hline 3 & $\begin{array}{l}\text { Ease of } \\
\text { Navigation }\end{array}$ & $\begin{array}{l}\text { Internal Search Engine } \\
\text { Simple and logical } \\
\text { architecture. } \\
\text { Broken Links } \\
\text { Link to external websites }\end{array}$ & $\begin{array}{l}\text { Internal Search engine is provided and its efficiency. } \\
\text { Simple navigational menu All } \\
\text { major links on home page } \\
\text { No broken links and no orphan pages. All } \\
\text { links working } \\
\text { Links to the external websites which visitor may frequently need is } \\
\text { provided. }\end{array}$ \\
\hline 4 & Informative & $\begin{array}{l}\text { Accurate } \\
\text { Complete } \\
\text { Relevant } \\
\text { Updates }\end{array}$ & $\begin{array}{l}\text { How correct Information is retrieved? No spelling or Grammar error? } \\
\text { Is information retrieved complete? } \\
\text { How much retrieved information is comprehensive? Archive } \\
\text { Information properly maintained and can be reached? } \\
\text { How frequently the information is updated? }\end{array}$ \\
\hline
\end{tabular}

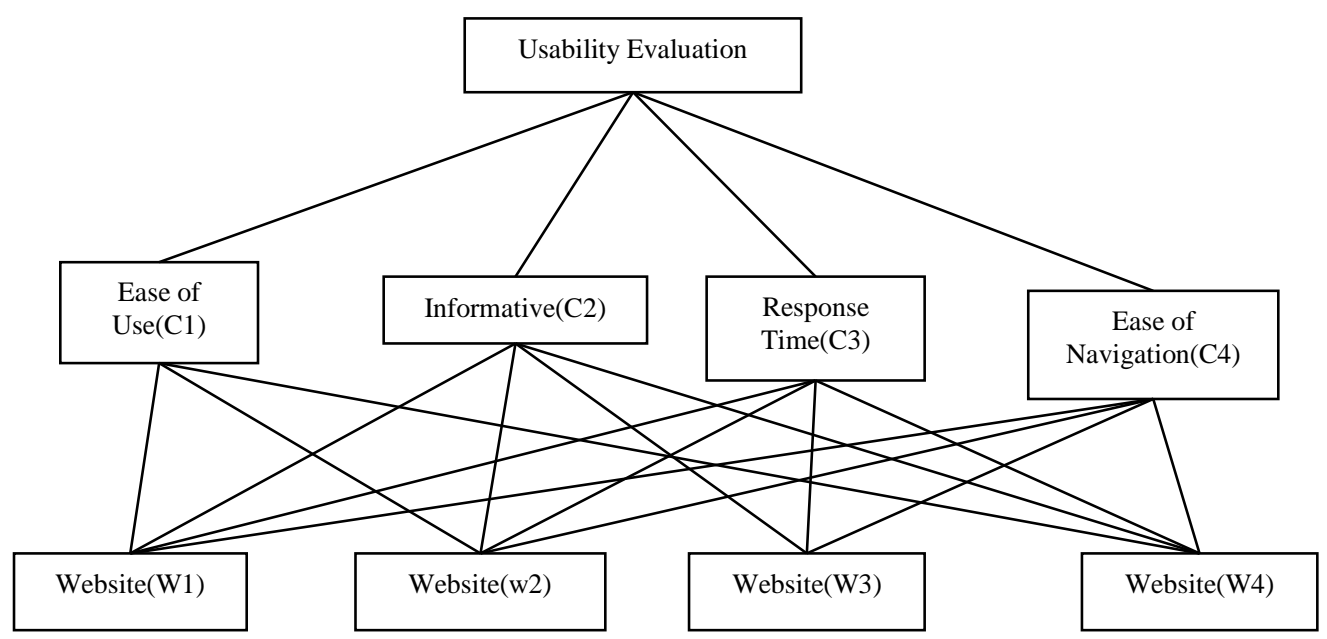

Fig 3: Hierarchal Structure 


\section{Ranking of Websites Using Fuzzy TOPSIS Approach}

TOPSIS approach proposed [10] based on the principle that among the alternative the chosen alternative should have the shortest distance from the ideal solution and farthest distance from the negative ideal solution which was later on extended in fuzzy environment.

(i). Using the Chen's methodology [15] the evaluation of three decision makers (DM's), a decision matrix with three alternatives with $\mathrm{m}$ alternatives $\left(\mathrm{W}_{1} \ldots \mathrm{W}_{\mathrm{m}}\right)$ based on four criteria's $\left(\mathrm{C}_{1} . . \mathrm{C}_{\mathrm{n}}\right)$ was assessed by Eq. (8).The elements $x_{i j}$ of the matrix indicates the performance rating of the $i^{\text {th }}$ alternative website corresponding to the $\mathrm{n}^{\text {th }}$ criteria w.r.t to the $\mathrm{n}^{\text {th }} \mathrm{DM}$.

$$
\mathrm{D}_{\mathrm{n}}=\left[\begin{array}{ccc}
\mathrm{X}_{11} & \mathrm{x}_{12} \cdots & \mathrm{x}_{\mathrm{in}} \\
\mathrm{X}_{21} & \mathrm{x}_{22} \cdots & \mathrm{X}_{2 \mathrm{n}} \\
\vdots & \vdots & \vdots \\
\mathrm{x}_{\mathrm{m} 1} & \mathrm{x}_{\mathrm{m} 2} & \mathrm{x}_{\mathrm{mn}}
\end{array}\right]
$$

Alternatives are evaluated w.r.t criteria by taking the preferences from DM's using the linguistic terms Table 5.

Table 5 Linguistic Terms for rating of website [22]

\begin{tabular}{|c|c|}
\hline Linguistic Term & TFN's \\
\hline Excellent(Ex) & $7.5,10,10$ \\
\hline High(H) & $5,7.5,10$ \\
\hline Good(G) & $2.5,5,7.5$ \\
\hline Low(L) & $0,2.5,5$ \\
\hline Very Low(VL) & $0,0,2.5$ \\
\hline
\end{tabular}

The DM's are website designer experts D1, D2, D3 and corresponding TFN's are presented in Table 6.

Table 6 Linguistic ratings of the alternative websites by different decision makers

\begin{tabular}{|c|c|c|c|c|}
\hline & $\mathrm{C} 1$ & $\mathrm{C} 2$ & C3 & $\mathrm{C} 4$ \\
\hline \multicolumn{5}{|l|}{ DM1 } \\
\hline W1 & $\mathrm{MG}$ & $\bar{G}$ & $\bar{G}$ & $\mathrm{G}$ \\
\hline W2 & $\mathrm{G}$ & VG & VG & $\bar{G}$ \\
\hline W3 & G & G & G & VG \\
\hline W4 & $\mathrm{F}$ & $\mathrm{G}$ & $\mathrm{F}$ & $\mathrm{MG}$ \\
\hline \multicolumn{5}{|l|}{ DM2 } \\
\hline W1 & $\mathrm{F}$ & G & VG & $\mathrm{G}$ \\
\hline W2 & VG & VG & VG & VG \\
\hline W3 & G & VG & VG & G \\
\hline W4 & MP & $\mathrm{F}$ & G & $\mathrm{G}$ \\
\hline \multicolumn{5}{|l|}{ DM3 } \\
\hline W1 & G & $\mathrm{MG}$ & G & $\mathrm{G}$ \\
\hline W2 & VG & $\mathrm{G}$ & G & VG \\
\hline W3 & $\mathrm{F}$ & MG & G & G \\
\hline W4 & $\mathrm{P}$ & $\mathrm{G}$ & MG & $\mathrm{G}$ \\
\hline
\end{tabular}

The linguistic variables shown in Table 6 are converted into TFN's. Table 7 represents the fuzzy numbers of the average of the judgments taken by decision makers using Table 5.

(ii). Normalize the fuzzy decision matrix using [15] as:

$$
v_{i j}=\left(\frac{u_{i j}}{u_{i j}{ }^{*}}, \frac{m_{i j}}{u_{i j}{ }^{*}}, \frac{u_{i j}}{u_{i j}{ }^{*}}\right) \text { where } u_{i j}^{*}=\max \left(u_{i j}\right)
$$

The calculated normalized fuzzy decision matrix is shown in Table 8

(iii). After calculating the normalized fuzzy matrix the weights calculated using FAHP approach as in Table 4, the weighted normalized fuzzy decision matrix represented by $\mathrm{z}_{\mathrm{ij}}$ is calculated as:

$$
\mathrm{z}_{\mathrm{ij}}=\mathrm{v}_{\mathrm{ij}} \times \mathrm{W}_{\mathrm{j}}
$$

Where $W_{j}$ Represents the importance weight of criteria $C_{j}$

$$
\mathrm{i}=1,2 . \mathrm{m} \text { and } \mathrm{j}=1,2, \ldots \mathrm{n}
$$

Weighted normalized matrix is shown in Table 9

(iv). For each criteria from weighted normalized matrix positive ideal (A+) and negative ideal values (A-) are determined. As EOU, EON, INF contributes positively and RT negatively to the usability, so the solutions are considered as:

$$
\begin{aligned}
\mathrm{A}^{+} & =\left(\mathrm{z}_{1}^{+}, \ldots ., \mathrm{z}_{1 \mathrm{n}}^{+}\right) \\
\mathbf{A}^{-} & =\left(\mathbf{z}_{1}^{-}, \ldots, \mathbf{z}_{1 \mathbf{n}}^{-}\right)
\end{aligned}
$$

Where

$$
\begin{gathered}
\mathrm{z}_{\mathrm{j}}^{+}=\max \left(\mathrm{z}_{\mathrm{ij}}\right)=1(\text { positive criteria }), \\
=0(\text { negative criteria }) \\
\mathrm{j}=1,2 \ldots \mathrm{n}, \\
\mathrm{z}_{\mathrm{j}}^{-}=\min \left(\mathrm{z}_{\mathrm{ij}}\right)=0(\text { positive criteria }), \\
=1(\text { negative criteria }) \\
\mathrm{j}=1,2 \ldots \mathrm{n},
\end{gathered}
$$

In the present study the calculated values of $\mathrm{A}^{+}$and $\mathrm{A}^{-}$ are:

$$
\begin{aligned}
A^{+} & =(0,0,0),(1,1,1),(1,1,1)(1,1,1) \\
A^{-} & =(1,1,1),(0,0,0),(0,0,0),(0,0,0)
\end{aligned}
$$

(v). Compute the distance from positive and negative ideal values for each alternative.

$$
\begin{aligned}
D_{i}^{+} & =\sum_{j=1}^{n} d\left(Z_{i j}, Z_{j}^{+}\right), \quad i=1 \ldots . m \\
D_{i}^{-} & =\sum_{j=1}^{n} d\left(Z_{i j}, Z_{j}^{-}\right), \quad i=1 \ldots . m
\end{aligned}
$$


Table 7 Fuzzy numbers of the average ratings of the alternative websites.

\begin{tabular}{|c|c|c|c|c|c|}
\hline & W1 & W2 & W3 & W4 & Weight \\
\hline C1 & $(4,6.5,9)$ & $(7,9.3,10)$ & $(4,7,9)$ & $(1,3.5,6)$ & $(0.15,0.34,0.7)$ \\
\hline C2 & $(5,7.5,9)$ & $(7,9.3,10)$ & $(5,8.2,10)$ & $(4,7,9)$ & $(0.10,0.17,0.34)$ \\
\hline C3 & $(7,8.7,10)$ & $(7,9.3,10)$ & $(7,8.7,10)$ & $(4,6.5,9)$ & $(0.06,0.06,0.08)$ \\
\hline C4 & $(7,8,9)$ & $(7,9.3,10)$ & $(7,8.7,10)$ & $(5,7.5,9)$ & $(0.15,0.43,0.96)$ \\
\hline
\end{tabular}

Table 8 Normalized Fuzzy decision Matrix

\begin{tabular}{|c|c|c|c|c|c|}
\hline & W1 & W2 & W3 & W4 & Weight \\
\hline C1 & $(0.11,0.15,0.25)$ & $(0.10,0.11,0.14)$ & $(0.11,0.144,0.25)$ & $(0.16,0.28,1)$ & $(0.15,0.34,0.7)$ \\
\hline C2 & $(0.5,0.75,0.9)$ & $(0.7,0.93,1)$ & $(0.5,0.82,1)$ & $(0.4,0.7,0.9)$ & $(0.10,0.17,0.34)$ \\
\hline C3 & $(0.7,0.87,1)$ & $(0.7,0.93,1)$ & $(0.7,0.87,1)$ & $(0.4,0.65,0.9)$ & $(0.06,0.06,0.08)$ \\
\hline C4 & $(0.7,0.8,0.9)$ & $(0.7,0.93,1)$ & $(0.7,0.87,1)$ & $(0.5,0.75,0.9)$ & $(0.15,0.43,0.96)$ \\
\hline
\end{tabular}

Table 9 Weighted Normalized Fuzzy Decision Matrix

\begin{tabular}{|c|c|c|c|c|}
\hline & W1 & W2 & W3 & W4 \\
\hline C1 & $(0.02,0.05,0.18)$ & $(0.02,0.04,0.10)$ & $(0.02,0.05,0.18)$ & $(0.02,0.1,0.7)$ \\
\hline C2 & $(0.05,0.13,0.3)$ & $(0.07,0.16,0.34)$ & $(0.05,0.14,0.34)$ & $(0.04,0.12,0.31)$ \\
\hline C3 & $(0.04,0.05,0.08)$ & $(0.04,0.06,0.08)$ & $(0.04,0.05,0.08)$ & $(0.02,0.04,0.07)$ \\
\hline C4 & $(0.1,0.3,0.86)$ & $(0.1,0.4,0.9)$ & $(0.1,0.37,0.9)$ & $(0.08,0.32,0.86)$ \\
\hline
\end{tabular}

The distance between $d\left(Z_{i j}, Z_{j}^{+}\right)$if $Z_{i j}=\left(l_{i j}, m_{i j}, u_{i j}\right)$ and $\mathrm{Z}_{\mathrm{j}}^{+}=\left(\mathrm{l}_{\mathrm{j}}^{+}, \mathrm{m}_{\mathrm{j}}^{+}, \mathrm{u}_{\mathrm{j}}^{+}\right)$is computed as [23]

$$
\mathrm{d}\left(\mathrm{Z}_{\mathrm{ij}}, \mathrm{Z}_{\mathrm{j}}^{+}\right)=\sqrt{\frac{\left[\left(\mathrm{l}_{\mathrm{ij}}-\mathrm{l}_{\mathrm{j}}^{+}\right)^{2}+\left(\mathrm{m}_{\mathrm{ij}}-\mathrm{m}_{\mathrm{j}}^{+}\right)^{2}+\left(\mathrm{u}_{\mathrm{ij}}-\mathrm{u}_{\mathrm{j}}^{+}\right)^{2}\right]}{3}}
$$

Using equation (13) the distance for alternative 1 w.r.t. criteria 1 is calculated as

$$
\mathrm{d}\left(\mathrm{Z}_{11}, \mathrm{Z}_{1}^{+}\right)=\sqrt{\frac{\left[(0-0.05)^{2}+(1-0.25)^{2}+(1-0.9)^{2}\right]}{3}}=0.11
$$

In the similar manner the distance between $\mathrm{d}\left(\mathrm{Z}_{\mathrm{i} j}, \mathrm{Z}_{\mathrm{j}}^{-}\right)$is calculated.

$$
\mathrm{d}\left(\mathrm{Z}_{11}, \mathrm{Z}_{1}^{-}\right)=\sqrt{\frac{\left[(1-0)^{2}+(0-0.08)^{2}+(0-0.45)^{2}\right]}{3}}=0.919
$$

(vii). The alternatives are ranked based on closeness coefficient $\mathrm{C}_{\mathrm{i}}$ as given in Table 10 .

\section{CONCLUSION}

$$
\begin{gathered}
\mathrm{D}_{\mathrm{i}}^{+}=\sum_{\mathrm{j}=1}^{\mathrm{n}} \mathrm{d}\left(\mathrm{Z}_{\mathrm{ij}}, \mathrm{Z}_{\mathrm{j}}^{+}\right)=2.56 \\
\mathrm{D}_{\mathrm{i}}^{-}=\sum_{\mathrm{j}=1}^{\mathrm{n}} \mathrm{d}\left(\mathrm{Z}_{\mathrm{i} j}, \mathrm{Z}_{\mathrm{j}}^{-}\right)=1.697
\end{gathered}
$$

Table 9 Distance from positive ideal solution

\begin{tabular}{|c|c|c|c|c|c|}
\hline & $d\left(Z_{i 1}, Z_{1}^{+}\right)$ & $d\left(Z_{i 2}, Z_{2}^{+}\right)$ & $d\left(Z_{i 3}, Z_{3}^{+}\right)$ & $d\left(Z_{i 4}, Z_{4}^{+}\right)$ & $D_{i}^{+}$ \\
\hline W1 & 0.11 & 0.846 & 0.943 & 0.663 & 2.56 \\
\hline W2 & 0.06 & 0.81 & 0.93 & 0.63 & 2.43 \\
\hline W3 & 0.109 & 0.831 & 0.943 & 0.637 & 2.52 \\
\hline W4 & 0.40 & 0.85 & 0.95 & 0.66 & 2.86 \\
\hline
\end{tabular}

(vi). Closeness coefficient $\left(\mathrm{C}_{\mathrm{i}}\right)$ of each alternative $\mathrm{i}$ with reference to negative ideal value $D_{i}^{-}$

$$
\begin{aligned}
C_{i} & =\frac{D_{i}^{-}}{\left(D_{i}^{-}+D_{i}^{+}\right)} \quad i=1 \ldots m \\
C_{1} & =\frac{1.697}{(1.697+2.56)}=0.398
\end{aligned}
$$

And using Equation (12)

The current study is done to enhance the web usability as per the viewer's opinion. This will encourage the people to visit the website and fetch the information and increase the popularity of the organization. The website $\mathrm{W} 2$ is ranked best among the given alternatives as it 
provides the maximum information if we compare with other alternatives.

In this paper Fuzzy TOPSIS method is used to rank a website as different users have different opinion for evaluating the websites. The factors that affect the usability of website are identified as Response Time, Ease of Use, Ease of Navigation, Informative and they were rated using linguistic term to incorporate the fuzziness of the decision maker's opinion. Three website developers were considered as decision makers. However the work can be extended by incorporating the opinion of different types of viewers of the websites like students, aspiring students, and parents along with expert designers as decision makers. Their contribution to decision can be calculated by giving suitable weightage to them. This will provides website manager a better understanding for people perception of those websites.

The Optimal combinations of parameters were chosen like maximum information \& least response time. However increase in amount of information may overload the website which may lead to decrease in response time. There should be a balance establish between information provided (informative) and Response time (RT). This work can be further extended by performing sensitivity analysis of the parameters.

Table 10 Ranking of alternatives based on closeness coefficient.

\begin{tabular}{|c|c|c|c|c|c|c|c|}
\hline & $d\left(Z_{i 1}, Z_{1}^{-}\right)$ & $d\left(Z_{i 2}, Z_{2}^{-}\right)$ & $d\left(Z_{i 3}, Z_{3}^{-}\right)$ & $d\left(Z_{i 4}, Z_{4}^{-}\right)$ & $D_{i}^{-}$ & $C_{i}$ & Rank \\
\hline $\mathbf{W 1}$ & 0.919 & 0.190 & 0.059 & 0.529 & 1.697 & 0.398 & 3 \\
\hline $\mathbf{W 2}$ & 0.947 & 0.22 & 0.06 & 0.571 & 1.798 & 0.425 & 1 \\
\hline $\mathbf{W 3}$ & 0.92 & 0.21 & 0.059 & 0.564 & 1.753 & 0.410 & 2 \\
\hline $\mathbf{W 4}$ & 0.86 & 0.193 & 0.047 & 0.53 & 1.63 & 0.36 & 4 \\
\hline
\end{tabular}

\section{REFERENCES}

[1] Nigel Bevan" Guidelines and Standards for Web Usability", Proceedings of HCI International, Lawrence Erlbaum, 2005.

[2] Renuka Nagpal, Deepti Mehrotra, Arun Sharma, Pradeep Bhatia" ANFIS Method for Usability Assessment of Website of an Educational Institute" World Applied Sciences Journal 23 (11): 1489-1498, 2013 ISSN 18184952 (c) IDOSI Publications.

[3] Mohammad Saber Iraji, Reyhane mosaddegh,"Object Oriented Software Usability Estimate with Adaptive Neuro Fuzzy, Fuzzy Svm", IJIEEB, vol.5, no.1, pp.40-49, 2013. DOI: 10.5815/ijieeb.2013.01.05.

[4] Saaty, T.L., "A scaling method for priorities in hierarchical structures". Journal of Mathematical Psychology, 1977. 15(3): p. 234-281.

[5] Charnes A, Cooper WW "Management Models and industrial applications of linear Programming" Wiley, 1961 New York.

[6] Roy B Classement et choix en presence de points de vue multiples: la methode ELECTRE.RIRO 8 1968:57-75.

[7] Roy B, Bertier P. La method Electre II: Une application au media planning. In: Ross M(ed) Vlleme Conference Internationale de Recherche Operationnelle, Dublin (1973), OR72, North Holland Amsterdam, pp291-302.

[8] Roy B, ELECTRE III: un algorithme de classement fonde' surune repre'sentation floue des pre'fe'rencesen pre'sence de crite res multiples.Cahiers du CERO (1978)20:3-24.

[9] Saaty TL, the analytic hierarchy process (1980). McGraw-Hill, New York.

[10] Hwang CL, Yoon $\mathrm{K} \mathrm{Multiple} \mathrm{attribute} \mathrm{decision}$ making (1981). Springer, Berlin.

[11] Brans JP, Vincke P, Mareschal B, How to select and how to rank projects: the PROMETHEE method (1986). Eur J Oper Res 24:228-238.
[12] Saaty TL, Decision making with dependence and feedback: the analytic network process(1996). RWS Publications, Pittsburgh.

[13] Zadeh LA, Fuzzy sets. Inf Control 8(91965): 338-353.

[14] Saaty, T.L.,How to make a decision: The analytic hierarchy process. European Journal of Operational research, (1990), 9-26.

[15] Chen CT., Extension of the TOPSIS for group decision making under fuzzy environment.Fuzzy Sets Syst 114(2000):1-9.

[16] Crystal Ip,Shanshan Qi, Rosanna Leung,Rob Law "Hotel Website Performance Evaluation: A Fuzzy Analytic Hierarchy Process Approach" International Conference on E-business and E- Government,2010.

[17] K.Srinivasan Raju,D.Nagesh Kumar"Multicriterion Analysis in Engineering and Management" PHI pp 125

[18] Zadeh LA The concept of linguistic variable and its application to approximate reasoning. Inf Science 1975; 8(2):199-249.

[19] H.J. Zimmermann, Fuzzy Set Theory and Its Applications, second ed., Kluwer Academic, Boston, 1991.

[20] W. Pedrycz, F. Gomide, Fuzzy Systems Engineering Toward Human-centric Computing, Wiley, New Jersey, 2007.

[21] Kaufmann, A. and M.M. Gupta 1985 Introduction to Fuzzy Arithmetic: Theory and Applications. Van Nostrand Reinhold, New York.

[22] Francisco Rodrigues Lima Junior , Lauro Osiro , Luiz Cesar Ribeiro Carpinetti(2014)," A comparison between Fuzzy HP and Fuzzy TOPSIS methods to supplier selection" Applied Soft Computing $21: 194-209$

[23] Opricovic,S. and G.H. tzeng,(2004) Compromise solution by MCDM methods: A comparative Analysis of VIKOR and TOPSIS,European journal of Operational Research,156,pp 445-455. 


\section{Authors' Profiles}

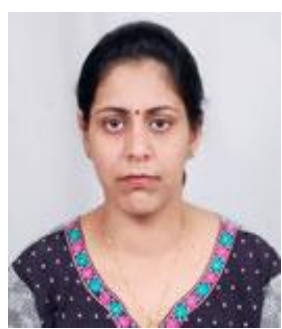

Renuka Nagpal working as Assistant Professor in Department of Computer Science, Amity School of Engineering and Technology, Amity University ,Uttar Pradesh. Currently she is pursuing her $\mathrm{PhD}$ in the field of Computer Science and Engineering from Uttar Pradesh Technical University, Lucknow. She completed her M.Tech in CSE from Guru Jambeshwar University Science and Technology, Hisar in 2001.

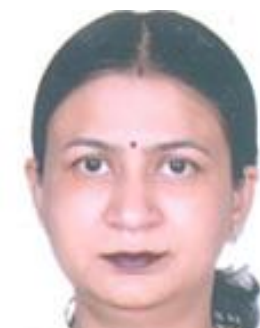

Dr. Deepti Mehrotra currently working as Professor in Amity School of Engineering and Technology in IT department. She completed her Phd from Lucknow University. She has more than 20 year of research, teaching and content writing experience. She had published more than 60 papers in international refereed Journals and conference Proceedings. She is editor and reviewer for many books, referred journal and conferences. She is regularly invited as resource person for FDPs and invited talk in national and international conference. She guided Ph.D. and M.Tech students.

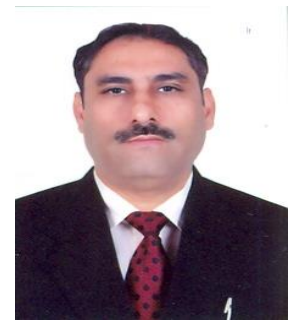

Dr. Pradeep Kr. Bhatia currently working as Professor in department of Computer Science and Engineering, Guru Jambeshwar University Science and Technology, Hisar. His areas of research are Software Quality, Software Metrics, Software Measure with fuzzy Technique and COTS, Computer Graphics. Prof. Bhatia has 58 publications in referred journals and conferences of international and national repute. He has been a member of a number of committee for various universities in various capacities.

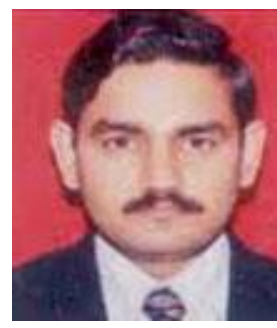

Dr Arun Sharma is currently working as Associate Professor in Indira Gandhi Delhi Technical University for Women, Delhi. He completed his M.Tech. in CSE from Punjabi University, Punjab in 1997 and $\mathrm{PhD}$ in Software Engineering from Thapar University, Punjab in 2009. $\mathrm{He}$ has published more than 40 research papers in Journals (including 10 in SCI/SCIE and 15 in SCOPUS indexed) and Conferences. His area of interest include software Engineering, Autonomic Computing and Soft Computing Techniques. He is on editorial board/advisory panel for various International Journals and Conferences.

How to cite this paper: Renuka Nagpal, Deepti Mehrotra, Pradeep Kumar Bhatia, Arun Sharma,"Rank University Websites Using Fuzzy AHP and Fuzzy TOPSIS Approach on Usability", IJIEEB, vol.7, no.1, pp.29-36, 2015. DOI: 10.5815/ijieeb.2015.01.04 